\title{
EREBEA
}

\author{
Revista de Humanidades \\ y Ciencias Sociales \\ Núm. 8 (2018), pp. 45-60 \\ ISSN: 0214-0691
}

\section{LA IMPOSIBILIDAD DE SEPARAR LO INMATERIAL DE LO MATE- RIAL EN LAS MANIFESTACIONES CULTURALES ${ }^{1}$}

Antonio Muñoz Carrión

Universidad Complutense de Madrid

María Pía Timón Tiemblo Instituto del Patrimonio Cultural Español

RESUMEN

El presente artículo revisa la manera en que Patrimonio Cultural Inmaterial ha sido tratado en la legislación española a partir de la Convención de la UNESCO del año 2003. Plantea la necesidad de considerar como una unidad las dimensiones materiales y las inmateriales en cualquier manifestación de la cultura, ya que ambos planos pierden sentido cuando son tratados por separado. En la mayoría de los casos hasta la actualidad, se han estudiado con metodologías diferentes, se han protegido con normas diferentes y se han planificado con políticas diferentes. Con el propósito de reconocer la inherente unidad entre la dimensión material y la inmaterial, se realiza un análisis de cómo ambos se manifiestan en los rituales festivos y en el ámbito de la gastronomía.

Palabras Clave

Patrimonio Cultural Inmaterial; tradición; conocimientos; expresiones; comunidades portadoras de la tradición; ritual; gastronomía.

Fecha de recepción: 9 de oct. de 2018

Fecha de aceptación: 30 de oct. de 2018
Abstract

This article reviews the way in which Intangible Cultural Heritage has been addressed within the Spanish legislation since the 2003 UNESCO Convention. It raises the need to consider the tangible and intangible dimensions of any manifestation of culture as a unit, since both aspects lose meaning when they are treated separately. In most cases until now, they have been studied following different methodologies, protected with different standards and planned with different policies. In order to recognize the inherent unity between the tangible and intangible dimensions, an analysis is made of how both appear in festive rituals and in the field of gastronomy.

\section{KeYwords}

Intangible Cultural Heritage; tradition; knowledge; expressions; tradition-bearing communities; ritual; gastronomy.

1 La bibliografía pertinente para este texto es la siguiente: J. Agudo Torrico, "Patrimonio etnológico: recreación de identidades y cuestiones de mercado", en PH Cuadernos, n.o 17. (Cap. 12), 2005; J. Agudo Torrico e I. Moreno Navarro, "Las fiestas andaluzas", en J. Agudo Torrico e I. Moreno Navarro (coords.): Expresiones culturales andaluzas. Sevilla: Aconcagua Libros, 2012, pp. 165-217; 
El TRATAMIENTO HOLÍSTICO DE LO MATERIAL Y LO INMATERIAL EN LA ACTUAL Legislación sobre Patrimonio Cultural inmaterial

Es indudable que las leyes son reflejo de la sociedad y del pensamiento de ese momento, respondiendo a una realidad que justifica su existencia y como tal si hacemos una comparativa del tratamiento que reciben los bienes patrimoniales comprobaremos que existe una gran diferencia en su tratamiento entre la Ley 16/1985 de Patrimonio Histórico Español y la 10/2015 de Salvaguardia del Patrimonio Cultural Inmaterial. En la primera, en su título VI de Patrimonio Etnográfico se presenta éste dividido en tres apartados: Bienes inmuebles, bienes muebles y conocimientos y actividades.

Precisamente aquí estriba una de las grandes diferencias entre estos dos tipos de patrimonio: el etnográfico y el inmaterial. Para el primero, los bienes materiales muebles son definidos como: el producto de actividades laborales, estéticas y lúdicas propias de cualquier grupo humano, arraigadas y transmitidas consuetudinariamente. Definición correcta, puesto que se asocia a la actividad, pero se

\footnotetext{
J. L. Alonso Ponga, "La construcción mental del patrimonio inmaterial", en Patrimonio Cultural de España, n. ${ }^{\circ}$ 0, pp. 45-63; J. Baudrillard, Cultura y simulacro. Barcelona: Kairós, 1984; J. Baudrillard, El complot del arte. Buenos Aires: Amorrortu, 2006; P.-L. Colon (ed.), Ethnographier les sens. París: Ed. Pétra, 2013; M. de Certeau, Livnention du quotidien. 1. Arts de faire. París: Gallimard, 1990; J. A. González Alcantud, Patrimonio y Pluralidad: Nuevas Direcciones en Antropología Patrimonial. Granada: Centro de Investigaciones Etnológicas Ángel Ganivet, 2003; M. Halbwachs, La memoria colectiva. Zaragoza: Prensas Universitarias de Zaragoza, 2004; D. Le Breton, El sabor del mundo. Una antropología de los sentidos. Buenos Aires: Nueva Visión, 2007; J. Marcos Arévalo, Objetos, sujetos e ideas. Bienes etnológicos y memoria social, Badajoz: Ayuntamiento de Badajoz, 2008; S. W. Mintz, Sabor a comida, sabor a libertad. México: Ediciones de la Reina Roja, 2003; A. Muñoz Carrión, "La creación colectiva: producción, comunicación y vivencia", en A. Iribas Rudín (ed.): La actitud del artista. Madrid: Clepsidra Ediciones, 2015, pp. 157-196; A. Muñoz Carrión, "El patrimonio etnográfico y la simulación de la cultura", en Areté Documental, n. ${ }^{\circ} 16$ (2002); A. Muñoz Carrión, "El patrimonio cultural material y el inmaterial: Dos caras de la misma moneda", en Areté Documenta, n. 21 (2005); S. Pink, Doing Sensory Etnography. Londres: Sage, 2015; V. Propp, "Lo específico del folklore", en Edipo a la luz del folklore. Madrid: Fundamentos, 1980, pp. 141-179; M. A. Querol, "El tratamiento de los bienes inmateriales en las leyes de Patrimonio Cultural", en Patrimonio Cultural de España, n. 0 (2009), pp. 71-107; M. P. Timón Tiemblo y J. M. Valadés, "La Etnografía como fuente documental en la restauración: San Antonio de la Florida", en Revista Pátina, n. 6 (1993), número especial "Homenaje a D. Raúl Amitrano", pp. 121-128; y Timón Tiemblo, M. P., "Frente al espejo: lo material del Patrimonio Inmaterial", en Patrimonio Cultural de España, n. 0 (2009), pp. 62-70.
} 
descontextualiza al separarse en otro epígrafe de dichas actividades. Es decir, la separación de lo material y lo inmaterial. Lo mismo ocurre con el tratamiento que se da a los inmuebles: edificaciones e instalaciones cuyo modelo constitutivo sea expresión de conocimientos adquiridos, arraigados y transmitidos consuetudinariamente y cuya factura se acomode, en su conjunto o parcialmente, a una clase, tipo o forma arquitectónicos utilizados tradicionalmente por las comunidades o grupos humanos. Sólo se han tenido en consideración los bienes inmuebles, pero no como espacios donde se desarrolla una manifestación cultural inmaterial, sino como modelos constructivos que responden a tipos utilizados tradicionalmente. Podemos afirmar que los espacios o lugares de desarrollo que son inherentes a las manifestaciones culturales inmateriales no se tuvieron en consideración en todo el título VI de la ley 16/85 de Patrimonio Histórico Español. Por último se habla de los: conocimientos o actividades que procedan de modelos o técnicas tradicionales utilizados por una determinada comunidad.

Estos tres elementos: muebles, inmuebles, conocimientos y actividades presentan en la definición del documento de la Convención para la Salvaguardia del Patrimonio Cultural Inmaterial de 2003, de UNESCO, una unidad, un todo, donde es difícil separar los bienes materiales, de los inmateriales y de su entorno o espacio de desarrollo. Esta misma definición de la Convención, en la que se define lo que es Patrimonio Cultural Inmaterial la ha adoptado la Ley 10/2015 de Salvaguardia del Patrimonio Cultural Inmaterial:

"Los usos, representaciones, expresiones, conocimientos y técnicas -junto con los instrumentos, objetos, artefactos y espacios culturales que les son inherentes- que las comunidades, los grupos y en algunos casos los individuos reconocen como parte integrante de su Patrimonio Cultural. Este Patrimonio Cultural Inmaterial, que se transmite de generación en generación, es recreado constantemente por las comunidades y grupos en función de su entorno, su interacción con la naturaleza y su historia, infundiéndoles un sentimiento de identidad y continuidad y contribuyendo así a promover el respeto de la diversidad cultural y la creatividad humana”.

De la visión compartimentada y dividida del Patrimonio Etnográfico contemplado en la norma del año 85 , hemos pasado a un tratamiento holístico de los elementos y valores que integran el Patrimonio Cultural Inmaterial. Es evidente en esta definición como se aúnan junto a las expresiones, actividades, técnicas y conocimientos, los instrumentos y artefactos que le son inherentes, así como el espacio de desarrollo.

Otra gran diferencia implícita en la propia definición es el protagonismo de las comunidades, los grupos, e incluso en algunos casos los individuos, al otorgarles 
la facultad de que sean ellos los que reconozcan si dichas manifestaciones forman parte de su patrimonio cultural. En este análisis de ambas leyes es interesante comprobar la importancia de las comunidades portadoras frente a las Administraciones. Digamos que se percibe para éstas más limitado el papel que históricamente se les ha venido dando. Pues no hay que olvidar que el PCI, incluye las manifestaciones vivas, experimentadas o rememoradas en tiempo presente, es decir que las comunidades y grupos siguen experimentando y que lógicamente son las conocedoras más directas. Es lógico por tanto que tengan un papel fundamental en todas las acciones de salvaguarda de ese patrimonio junto a las administraciones competentes. Sin embargo, en el Patrimonio Etnográfico se incluyen tanto las manifestaciones del pasado como las del presente: bienes muebles e inmuebles y los conocimientos y actividades que son o han sido expresión relevante de la cultura tradicional... Concepto este, el de tradicional, un tanto controvertido para el PCI, dado que considera a la manifestación como un elemento en continuo cambio, que se recrea y se trasmite, por supuesto la mayoría de las veces con una gran carga de tradición.

En la nueva Ley de Salvaguardia del Patrimonio Cultural Inmaterial 10/2015, consciente de la importancia que tienen los bienes muebles y espacios vinculados para el desenvolvimiento de las Manifestaciones Culturales Inmateriales, incluso se contemplan medidas de protección conforme a la legislación urbanística y de ordenación del territorio por parte de las administraciones competentes, si es que se requieren para la salvaguardia y desarrollo de dichas manifestaciones.

Resumiendo: las diferencias entre el tratamiento del Patrimonio Etnográfico y el Inmaterial, diríamos que en cuanto a concepto, el primero es mucho más técnico-científico, mientras que el PCI tiene un cariz más político-administrativo. Además, el tratamiento del segundo respecto a los distintos elementos culturales que lo integran presenta una visión holística de los mismos, sin divisiones entre lo material y lo inmaterial. En cuanto a la patrimonialización de cada uno de ellos, podemos afirmar que el etnográfico, se patrimonializa y patrimonializaba de arriba abajo (Top-Down), es decir tomando el protagonismo y la potestad de hacerlo las Instituciones y Organismos. Por el contrario, el Patrimonio Cultural Inmaterial se patrimonializa de abajo arriba (Botton-up), tomando el protagonismo las comunidades, grupos e individuos, como portadores, que crean, mantienen y transmiten este patrimonio, asociándolos por ello activamente a la salvaguardia del mismo.

No podemos olvidar que con respecto al protagonismo de las comunidades y grupos en las acciones de salvaguardia del Patrimonio Cultural, ha tenido y tiene una gran importancia la evolución propia del Estado Social y Democrático de Derecho. Ésta ha producido una crisis irreversible de los principios técnicos-jurídicos que fundamentaban las doctrinas de Protección, como eran: la concepción absoluta del derecho de propiedad, ahora limitada. Es patrimonio de la comunidad, entrando en juego el interés público sobre el privado y recobrando ahora mayor protagonismo la sociedad frente a los poderes públicos. 
LAS DIFICULTADES QUE ENCIERRA EN LA PRÁCTICA VALORAR MÁS LO MATERIAL SOBRE LO INMATERIAL O A LA INVERSA

Efectivamente la práctica nos demuestra que no podemos valorizar más lo material que lo inmaterial y a la inversa. Hay muchos ejemplos. En algunos casos el interés de los responsables científicos choca con el de la propia comunidad, anulándose los valores inmateriales para primar los materiales. ¿Entenderíamos la supresión de un paso procesional en una colectividad para la cual la imagen tiene, desde su origen para ella, un valor devocional que supera lo artístico? Esto sería lo correcto si el restaurador-conservador considera que la obra peligra, pero a veces -aunque evidentemente se trata de temas muy comprometidos- cabría preguntarse si no es preferible que la imagen siga cumpliendo la función social para la que fue creada, aunque no se garantice una larga permanencia en el tiempo. Citaremos, al respecto, la intensa polémica suscitada en el verano de 1992 a raíz de la restauración de la imagen de Nuestra Señora de África, patrona de Ceuta. Los restauradores aconsejaron que se suprimiera la salida procesional de la imagen con objeto de asegurar su conservación física, pero la medida no fue completamente entendida por la comunidad, quedando dividida la opinión pública de la ciudad en dos bandos: defensores y detractores de la procesión respectivamente. Incluso ello generó un reproche mutuo en ambos bandos de no ser buenos ceutíes al no honrar adecuadamente a su patrona.

Se nos olvida que el PCI tiene una carga importante de emoción, de devoción, de sentimiento, de anhelo, la cual muchas veces no se tiene en consideración y que quizá para la comunidad portadora es lo prioritario. De la misma manera ocurrió, con la práctica ritual, de carácter propiciatorio y de rogativa, que consistía en prender papel moneda con alfileres en los mantos de determinadas vírgenes durante algunas procesiones, y que desapareció ante la necesidad impuesta de "conservar" el manto. No estamos primando lo intangible sobre lo tangible, pero sí hay que analizar todo el sustrato emotivo-sentimental que conllevan la supresión de determinadas prácticas rituales. Consideramos que siempre puede existir un diálogo con la comunidad portadora para garantizar copias, o réplicas que permitan la continuidad de la práctica.

En otros casos la pérdida de la esencia de la manifestación inmaterial estriba en la desaparición de determinados objetos u artesanías estrechamente ligadas a prácticas inmateriales, considerando que la ausencia de esos objetos artesanales imposibilita tales manifestaciones. Eso ocurre con determinadas Manifestaciones Culturales Inmateriales que se pierden porque los elementos materiales que se usan en ellas, como calzado específico, indumentaria, palos, cintas, palmas trenzadas, etc., ya no se realizan porque se han olvidado las técnicas tradicionales de factura, o bien porque su fabricación no compensa económicamente. 
VAloraciones, Significaciones E INTERPRETACiONeS DEL PCI EN DOS DE SUS ÁMBITOS: EL DE LOS RITUALES FESTIVOS Y EL GASTRONÓMICO.

A continuación, realizaremos dos análisis, desde la perspectiva de la antropología, de algo tan inmaterial como es un ritual festivo y tan material como puede ser la comida, para demostrar que uno y otro, están revestidos e impregnados tanto de valores inmateriales como materiales, de manera indistinta, hasta el extremo de que toda escisión entre estos dos planos hace perder gran parte del sentido a cada una de ellos.

\section{Rituales festivos}

Para comprender la incorrección epistemológica que se deriva de la separación en las manifestaciones del PCI de la dimensión material y la inmaterial es necesario comenzar reflexionando sobre si tiene fundamento y aporta algo dicha escisión en el tratamiento de las producciones de la cultura. $\mathrm{O}$, si por el contrario, nos acerca de manera sesgada y engańosa a la misma.

Un ámbito ideal para entender cómo se relacionan estos dos planos lo tenemos en los rituales festivos, ya que son vivos y exigen la presencia de componentes culturales heterogéneos, aunque dichos rituales estén clasificados como inmateriales.

Los rituales festivos se suelen considerar patrimonio cultural inmaterial porque, entre otras razones, son actividades, expresiones y representaciones culturales vivas, asociadas a significados particulares y con capacidad para despertar sentimientos colectivos compartidos y con raigambre en una comunidad. Pero son, además, acción real y expresión, vivencia y comunicación. Por constituir creaciones específicas, las producciones rituales y festivas, junto con sus normas de organización, sus procesos y sus códigos de significación, forman parte primordial del ethos de la comunidad que las celebra. Cobran relevancia social a partir de su estética, de las emociones que despiertan en sus protagonistas y de la manera en que se encuentran interiorizadas en la población. La transmisión a las nuevas generaciones debe realizarse con continuidad y generalmente comienza en la infancia. Cuando están vivas y arraigadas es cuando se consideran patrimonio cultural, porque existe una voluntad decidida, por parte de sus protagonistas, de mantenerlas en el tiempo, de escenificarlas y de experimentarlas. Son, además, experiencias en donde se confirma y refuerza, en el presente y de cara al futuro, la identidad de sus participantes.

Por lo general, cuando la sociedad cambia bruscamente en sus estilos de vida, o se producen relevos generacionales radicales, la transmisión se debilita y este patrimonio pierde vitalidad, se fosiliza o sufre embates. Con frecuencia sucede que estas vivencias culturales son desplazadas por otras de nuevo diseño que, además, acaban aportando al grupo social, nuevas formas de identidad más ajustadas a las demandas del presente que las proporcionadas por el modelo tradicional basado en la repetición. 
El recorrido que suele seguir el PCI en su estrategia de reproducción suele alternar entre dos direcciones: La primera es aceptar nuevas funciones, que pueden ser inéditas y muy alejadas de las que motivaron su celebración durante siglos. La segunda es conservar prioritariamente la materialidad, y por tanto la forma, es decir, el aspecto exterior de la manifestación, y reivindicar las funciones originales que motivaron su celebración en etapas históricas anteriores.

Pero el hecho más novedoso y preocupante, a la vez que el menos tratado, es que algunas celebraciones parecen pervivir hoy prácticamente en sus formas, sin que casi nadie se cuestione por qué. Esta última opción es cada vez más habitual, dada la relevancia que ha cobrado, en nuestra experiencia del mundo, la dimensión visual del mismo, frente a la conceptual y emocional. Las generaciones de jóvenes actuales son herederas de una educación que prima en todos los planos del aprendizaje la percepción a través de la imagen frente a la provocada por el mundo que perciben cualquiera de los demás sentidos.

La característica principal que tienen las actividades consideradas patrimonio cultural inmaterial es que los elementos o situaciones que han motivado gran parte de ellas, sobre todo cuando nos referimos a las celebraciones festivas, con frecuencia han desaparecido, se han olvidado o no son accesibles (formas de vida ancestral, actividades sobre el medio, acontecimientos especiales, catástrofes, eventos históricos, batallas, apariciones, milagros, etc.); sin embargo, los procedimientos prácticos de rememoración se han ido perpetuando, y de hecho han logrado mantener una cierta continuidad en el tiempo, lo cual nos proporciona los indicios a partir de los cuales las podemos seguir considerando vivas.

Estos procedimientos de celebración se apoyan en acciones asociadas a dimensiones materiales (herramientas, vestimentas, objetos, artefactos, alimentos, etc.), mientras que las motivaciones o efectos que cada celebración festiva tienen sobre sus protagonistas son de diverso orden, por ejemplo: formas particulares de percepción, significados sentimientos, emociones, etc.; es decir, lo que se suele considerar como patrimonio cultural inmaterial.

Preocuparse por el plano de la expresión, en términos semióticos, es decir de lo que percibimos, porque es material y accesible a nuestros sentidos, sesga la concepción global del conjunto de un ritual, si no se logra establecer cuál es el verdadero plano del contenido y las vivencias colectivas derivadas del mismo para los participantes.

Estas disociaciones no son nuevas ni específicas del patrimonio cultural inmaterial. Hace casi cuatro décadas J. Baudrillard (1984) ya advirtió de esta tendencia en relación a la experiencia de la vida social en general, en la que se estaban implantando simulacros de la realidad, cada vez más perfectos, en todos los órdenes. En particular, señaló las fases sucesivas que habían seguido el reino de las imágenes. Observó que inicialmente las imágenes eran el reflejo de la realidad; que posteriormente empezaron a revestir y desnaturalizar dicha realidad, para continuar enmascarando "la ausencia de realidad profunda", y finalizar, en la úl- 
tima etapa, emancipándose completamente de aquella realidad primigenia y convertirse en su simulacro. En este momento se estaba desafiando la vieja noción de realidad. A veces, las manifestaciones rituales vividas pueden llegar a confundirse con su representación, por ejemplo, en el caso en que se doblan icónicamente, en directo, en el propio pueblo que las celebra, como cuando se retransmiten sus propias imágenes en la plaza proyectándolas en grandes pantallas en las calles. Esta transmisión puede llegar a duplicar, o incluso a eclipsar y sustituir a la propia celebración real.

\section{Permanencia o CAMBio}

Uno de los problemas que está surgiendo en la transformación del PCI procede de la forma particular en que sigue perviviendo en nuestros días. Tras la materialidad de las manifestaciones actuales del PCI subyace otro discurso comunicativo, de carácter identitario, que es tan importante y legítimo como el originario, consolidado históricamente. Se está generando un debate, dentro y fuera de las comunidades protagonistas, sobre si es conveniente actualizar las formas de llevar a cabo estas prácticas, siguiendo los sistemas de valores de nuestros días o, si por el contrario, es más conveniente atenerse a valoraciones, significaciones e interpretaciones propias de épocas anteriores. Lo hemos visto recientemente, por ejemplo, en los casos de los toros e Medinaceli, Tordesillas, Coria, etc., o en el Alarde de Fuenterrabía.

La posición que prima la apropiación, en el sentido señalado por Michel de Certeau (1990), desde criterios contemporáneos de la acción ritual material, intrroduce resignificaciones que afectan a la comunidad en el presente. Otra posición más conservadora es la que prima la entrega de la celebración exclusivamente a significados consolidados en la memoria colectiva. Su pretensión se sitúa en el plano de la rememoración. Esta última opción presupone que la dimensión simbólica se degrada con cualquier tipo de actualización de la dimensión formal de los significados asociados y fijados a la misma. No es este el lugar para desarrollar las consecuencias de una u otra opción, pero sí para tomar nota de que el plano de la interpretación, y el consenso comunitario sobre la misma, condiciona el desarrollo y el sentido de las ejecuciones materiales, es decir, de las figuraciones y las escenificaciones prácticas. Pero sin olvidar que la manera en que se lleve a cabo una celebración genera nuevos niveles de significado que se agregan y conviven con los anteriores, produciéndose un sincretismo que deberá ser documentado y no considerado como una desviación o como una transgresión.

En un mundo cada vez más globalizado, las formas de vida están más estandarizadas y ello afecta a la resignificación de estos símbolos revividos en los rituales y prácticas sociales materiales. La especificidad interna de gran parte del patrimonio cultural vivo, tanto en la forma como en el fondo, va cediendo a favor de una estandarización que facilita el acceso y la comprensión a todo tipo de públicos. Esta presión la sufren todas las manifestaciones sociales arraigadas, y es ejercida 
por parte de agentes sociales de distinto tipo. La mayor interferencia se deriva de la difusión y consolidación de valoraciones de corte mediático sobre las distintas expresiones culturales, sugiriendo así modelos ideales de éxito turístico marcado por la afluencia de públicos a dichas manifestaciones.

Las preguntas por resolver son: ¿en manos de quién o quiénes está la interpretación y el sentimiento asociado a una práctica ritual determinada?, ¿quiénes son sus legítimos destinatarios y en quiénes recaen los efectos simbólicos perseguidos con su celebración?, ¿podemos separar la ejecución material de dichas dimensiones emocionales inmateriales?, ¿siguen siendo patrimonio cultural las ejecuciones en sí mismas, sin esos efectos identitarios y emocionales, o deberíamos rehabilitar para esta situación otras categorías, como pasatiempos públicos, teatro de calle...etc.?

Por otra parte, un ritual festivo no lo es solo en el momento concreto de su manifestación expresiva. Las expresiones valoradas como patrimonio por sus autores ocupan espacios y se desarrollan en momentos ajenos exteriores y previos a la celebración, sin los cuales no podrían llegar a realizarse. Durante esos momentos de preparación se llevan a cabo otras actividades de carácter tangible, a la vez que se generan y consolidan relaciones interpersonales transcendentales para la celebración final. Estos contextos constituyen también ámbitos de aprendizaje de pautas de percepción intangible particulares asociadas a una práctica tangible, ya que en estas actividades rituales intervienen instrumentos musicales, vestimentas, objetos, artefactos, comidas y bebidas específicas. También, como veremos a continuación, repertorios de movimientos ejecutados de manera determinada, gestos característicos asociados y todo tipo de destrezas requeridas para la realización correcta de cada acción. El conjunto sensorial resultante, como señala David Le Breton (2007), es también unitario; es decir, no puede descomponerse ni tratarse a partir de estímulos distintos y diferenciados.

Tampoco las múltiples acciones que se ejecutan en la celebración deben ser consideradas escindibles entre sí, ya que están estructuradas y cobran su sentido pautadas desde los modelos únicos consolidados en la tradición y actualizados por los portadores de la misma. Dichas acciones tienen carácter práctico, pero constituyen a la vez mensajes complejos, dado que afectan directamente a los sentidos, y se asocian, a un imaginario colectivo local, al haber sido aprendidas desde la infancia. A la vez, no se circunscriben únicamente al universo mental de cada individuo, ya que han sido asumidas desde la experiencia compartida. Este complicado proceso basado en la acción, interacción y comunicación genera un "nosotros grupal" que no tiene equivalente en la vida cotidiana, porque aúna y no escinde, ya que genera una unidad entre todos los planos descritos que es específica en cada celebración. Estas acciones rituales parecen "hablar" por sí solas en cada ejecución práctica del ritual festivo. La legitimidad de la que se revisten, por más "exóticas" que dichas manifestaciones puedan parecer a ojos de un foráneo, la obtienen gracias a su actualización periódica. Es decir, surge de la celebración en donde se armonizan, renuevan y refuerzan, al mismo tiempo, las relaciones entre 
los individuos de la comunidad. Esa armonía que aúna a los participantes no es diseñada desde fuera, sino que se genera desde la parte nuclear del endogrupo y por ello la consideramos uno de los secretos más creativos, propios y, a la vez, menos estudiados del éxito de todo ritual. De hecho, en sus manos está la producción de ese "nosotros" al que apelan los participantes para legitimar toda acción vivida, sentida y no justificada con categorías exteriores al propio rito. Las frases elegidas para contestar, cuando se les pregunta a los ejecutantes desde fuera del ritual, cuál es la razón de esa práctica ritual y de la emoción desencadenada tras la misma son, casi siempre, las siguientes: "esto no se puede explicar con palabras", o también: "para entenderlo hay que ser de aquî".

Por tanto, el marco espacial, sus límites, la preparación previa, la sintaxis de un recorrido en una manifestación colectiva, así como los diferentes momentos significativos, como el comienzo, desarrollo y finalización, con sus mecanismos señalizadores (campanas, pirotecnia, música, percusión, ruidos espaciales, etc.) y las reglas que se deben cumplirse comportan, por sí mismos, una mutiplicidad de marcas y de señales con significado. En todo caso comportan una dimensión inmaterial no escindible en ningún caso de los elementos matéricos usados para su expresión pública.

También son patrimonio cultural, en el que no cabe separar la dimensión material de la inmaterial, los conocimientos del ámbito artesanal asociados a la preparación de cualquier ritual, transmitidos de generación en generación, acompañados de sus jergas y de sus significados específicos. Así como los códigos que subyacen a estas formas de expresividad o de actividad artesanal, tanto los verbales (lengua y habla) como no verbales, me refiero con éstos últimos a los proxémicos (el lenguaje del espacio) y a los kinésicos (el lenguaje de la expresión corporal y del gesto). Todo ello constituye un conjunto de rasgos organizados en patrones culturales consolidados que deben integrar la dimensión material y la inmaterial como un todo.

Si no se trabaja en la investigación de modelos que integren lo que constituye el PCI, es decir, la acción, las dimensiones expresivas y estéticas, los códigos de organización de la praxis concreta, las estructuras cognitivas clasificadoras y las vivencias y efectos simbólicos resultantes de la manifestación cultural final, estaremos abordando este tipo de patrimonio de una manera sesgada, fragmentada e incompleta. La consecuencia será que no lo comprenderemos en su totalidad, ni podremos diseñar apoyos para su salvaguarda, cuando se encuentre en peligro de desaparición.

No sólo las obras o celebraciones, con sus códigos internos, sino los mecanismos diversos de autoorganización y de autogestión, también deben ser considerados como parte fundamental del patrimonio cultural considerado inmaterial. Por tanto, debería garantizarse apoyo técnico a los mismos por parte de los expertos (antropólogos, comunicadores, sociólogos, juristas, economistas, etc.), designados por las administraciones autonómicas y por la administración estatal. En la actua- 
lidad se está produciendo un debate sobre el tratamiento de excepción que podrían tener algunas actividades del PCI por parte de las distintas normativas administrativas. Sería deseable que las administraciones que dictan normas en relación con las actividades socioculturales fueran capaces de coordinarse para reconocer la excepcionalidad de prácticas culturales que no pueden cumplir estrictamente, a causa de su especificidad, con las normativas habituales, sean procedentes de la UE, de la Administración Central, de la Autonómica o de la Local. En ocasiones se ha observado que existen departamentos administrativos que valoran prácticas culturales que están limitadas o prohibidas por normativas de otros departamentos. Por ejemplo, puede haber contradicciones entre departamentos que sean responsables de la cultura, la sanidad, las obras públicas o la construcción. Dichas contradicciones suelen afectar en mayor medida a la creatividad y a la actividad artesana, pero también a otros ámbitos propios del patrimonio cultural.

\section{LA DOCUMENTACión DEL PCI}

Documentar el PCI es otro problema que debe tratarse con urgencia. A veces se considera que la documentación recogida en un momento dado, a propósito de una actividad cultural, pueda ser suficiente para garantizar la perpetuidad de dicha práctica. Sin embargo, la realidad es que los bienes culturales se transforman constantemente en el tiempo, tanto en la dimensión denominada material como en la inmaterial, de forma paralela o alternativa, aunque lo hagan en dimensiones microscópicas. Dicha transformación tiene dos características: se produce a un ritmo tan lento que apenas es perceptible desde la escala temporal del ciclo vital de un ser humano. Por otra parte, esta transformación se suele producir, en mayor medida, en relación a los significados atribuidos y a las emociones generadas. Sin embargo, puede ser mucho más evidente en las dimensiones materiales accesibles a los sentidos, en concreto a todo lo visible. Es mucho más fácil conservar estable la dimensión visual de una manifestación cultural que perpetuar su sentido profundo.

En nuestra sociedad, de primacía visual, parece tranquilizar que la forma de los ritos se conserve inamovible y que ello se constate a nivel de la imagen. Se valora que lo accesible a la mirada siga ahí, como siempre, en escena. Al mismo tiempo, cada día que pasa, el significado y el simbolismo de dichos ritos, de apariencia estable, son pasto de apropiaciones por diversos agentes sociales. Es muy difícil determinar, si se observa el ritual solamente en su expresión formal, si dichos significados profundos han cambiado, se han arraigado de forma generalizada, o están el proceso de olvido y cuál es la razón de su estado y de su vitalidad. Y es que, para definir, evaluar y preservar el patrimonio inmaterial, lo que ha acabado primando en la sociedad actual, especialmente tras la intervención del turismo, son indicadores fundamentalmente materiales, visibles y reproducibles en imágenes. A veces, parece que la función de algunas fiestas fuera convertirse en escenarios primigenios o exóticos para la realización de selfies por parte de los visitantes. 
Estas páginas pueden considerarse una alerta sobre el hecho de que se esté descuidando el registro de las vivencias más subjetivas, tanto de carácter emocional, como de las relacionadas con construcciones cognitivas peculiares, asociadas a estas prácticas, en favor de documentos audiovisuales espectaculares centrados en la dimensión material. También es preocupante el hecho de no contar con una documentación sistemática acerca de la dimensión procesual, es decir, del cambio de las mismas, que se podría detectar mediante la realización sistemática de historias de vida de los protagonistas, entre otros indicadores.

Deberían también incluirse registros que recogieran nítidamente las dimensiones identitarias y emocionales vivas despertadas por cada ritual tratado, así como sus transformaciones y los motivos de éstas. Las tecnologías audiovisuales están muy desarrolladas y permiten realizar la documentación acerca del plano formal con facilidad y a un costo muy bajo. Las nuevas tecnologías $3 \mathrm{D}$ nos prometen un avance todavía superior en este campo. Pero la realidad es que esta tarea se suele reducir a filmar y generar un discurso audiovisual que servirá, supuestamente, como prueba de realidad del estado de la manifestación concreta. Sin embargo, la indagación sobre los simbolismos más profundos asociados a esas prácticas exige un trabajo de campo profesional que, con frecuencia, requiere ser realizado por antropólogos dentro y fuera de dichas prácticas, a la vez que una interpretación multidisciplinar para la que no se han creado todavía modelos, dada la compartimentación del conocimiento que existe en la formación de los expertos en patrimonio cultural.

El resultado es que contamos cada vez con más imágenes y audiovisuales que presumen en describir lo que denominamos patrimonio cultural inmaterial, pero que, en realidad, se refieren casi en exclusiva a lo que consideramos aspectos materiales visualizables de la cultura. En la era audiovisual actual estamos llegando a ahogar los significados internos y diversos vividos por los protagonistas de los rituales por imágenes de su dimensión exterior.

Por otra parte, conviene recordar que nunca existe una manifestación definitiva, ya que toda producción cultural siempre está sujeta a posibles desviaciones y cambios; por tanto, tampoco es aceptable un documento que las describa e interprete definitivamente. Las versiones canónicas de un ritual o de una fiesta, acaban centrándose inevitablemente en una celebración, con fecha concreta. Este nivel de concreción detiene el tiempo y con ello parece reivindicar un cierto carácter definitivo de la misma. A la vez tiene consecuencias perversas, ya que sus resultados, de cara a las nuevas generaciones, se convierten en una manera de fosilizar la vitalidad de su desarrollo y de su potencial creativo, encorsetándolas a partir de su descripción visual.

La transmisión intergeneracional de los actos rituales y de las vivencias asociadas se realizaba, antes de proliferar los medios de registro audiovisual, a través de un lento proceso de socialización. Los niños iban interiorizando los patrones desde los que más tarde abordarían esa experiencia mediante la imitación, acompañada de la comunicación oral que se les proporcionaba. Dicho procedimiento 
de transmisión no debería ser sustituido por la exposición a audiovisuales usados en museos o escuelas, a modo de tutoriales, del ritual concreto. Los rituales no son solo formas de hacer, sino de experimentar y de pensar una realidad; son vivencias específicas que integran instrumentos, acciones, expresiones, cognición y emoción en un modelo totalizador.

\section{Gastronomia y comensalidad}

No podemos olvidar que la gastronomía es el estudio de la relación del ser humano con su alimentación y su medio ambiente y de su entorno socio cultural. Será por ello también un símbolo territorial, una muestra tanto de la cultura como de la naturaleza que nos arraiga a un determinado lugar. Comprende a su vez un conjunto de conocimientos, de prácticas, rituales, tradiciones y símbolos relacionados con: los cultivos y cosechas agrícolas, con la caza, la pesca y la cría de animales, con los procesos de transformación de alimentos, así como con su cocinado, presentación, distintas formas de consumo, etc.

Además cada sociedad dispone de unas reglas, generalmente no escritas, de acuerdo a criterios varios: nutricionales, culturales o simplemente emocionales. No comemos sólo para alimentarnos, sino también por razones ceremoniales y sociales. Podemos decir que en función de determinadas situaciones existen expresiones alimentarias específicas. Diversas comidas del ciclo de la vida, del litúrgicofestivo, etc., nos lo ponen de manifiesto. Es por ello que los condicionamientos socio-culturales determinarán las formas de alimentación de una comunidad, siendo poderosos y complejos: las categorizaciones de los diferentes alimentos, los principios de asociación y de exclusión de alimentos, las prescripciones y las prohibiciones tradicionales y religiosas, etc. Por otro lado, las pautas actuales alimenticias encierran también una mezcla compleja y confusa de hábitos del pasado mezclados con constreñimientos y normas higiénico- sanitarias contemporáneas que ha contribuido a nuevas resignificaciones de determinados alimentos.

A lo largo de los siglos, alińos y especias han sido utilizados como conservantes, convirtiéndose en elementos muy importantes para el comercio y las relaciones entre territorios, generando importantes rutas e incluso propiciando el descubrimiento de nuevos horizontes. Pero también estos elementos en la comida nos aportan una dimensión extrasensorial, bien por el aroma o por el contacto con las papilas gustativas y el paladar, convirtiéndose en referencias importantes de la elaboración de los platos en las distintas tradiciones gastronómicas. Orégano, tomillo, albahaca, azafrán, comino, canela, nuez moscada, pimienta, pimentón, clavo, anises, entre otros, sazonan nuestras cocinas. Los sistemas de conservación han sido variados a lo lago de la historia, predominando los adobos de sal, aceite, vinagre, pimienta y pimentón. La técnica del secado con alguno de estos ingredientes, el ahumado, y la inmersión en aceite y manteca han sido recursos frecuentes de conservación. 
Para todas estas técnicas de conservación, mantenimiento, preparación y consumo de los alimentos se ha desarrollado todo un conjunto de objetos específicos, tanto para sólidos como para líquidos. Esto determinó una gran cantidad de oficios artesanos vinculados a estos objetos materiales, de barro, madera, hojalata, fibras vegetales, pieles de animales, etc.

En cuanto a los escenarios o los marcos espaciales de desarrollo son variados desde la mesa, comedores, merenderos, a los mercados locales de alimentos, pues desempeñan estos últimos un papel fundamental como lugares de intercambio. Son espacios culturales y focos de transmisión en los que además de la práctica cotidiana de comprar y vender se fomentan la concordia y las relaciones sociales.

Por otro lado, la gastronomía y determinados productos alimenticios tienen un lugar en el imaginario colectivo, por ejemplo, en algunos pueblos manchegos, donde el cultivo del azafrán ha sido y sigue siendo una actividad económica de importancia, han trascendido al imaginario colectivo determinadas creencias relacionadas con este producto. Pervive la costumbre de regalar unas briznas de azafrán a las parejas de novios, como símbolo propiciatorio de prosperidad. Ese imaginario se refleja también a través de los conocimientos y sabidurías que están recogidos en la literatura popular y la tradición oral, a través de refranes, proverbios, dichos, etc. Agua por San Juan, quita vino y no da pan; por agosto, ni pan ni mosto.

La gastronomía de la misma manera ha determinado roles específicos en la sociedad: Por ejemplo, las mujeres desempeñaban un papel fundamental en la transmisión de las competencias y conocimientos relacionados con la comida, salvaguardando las técnicas culinarias, respetando los ritmos estacionales, observando las fiestas del calendario y transmitiendo los valores de este elemento del Patrimonio Cultural a las nuevas generaciones. En una actividad tan tradicional en toda el área mediterránea como es la matanza del cerdo, las funciones y papeles de hombres y mujeres han estado claramente delimitados. En la actualidad, afortunadamente, en cuanto al género, la definición de los roles en las actividades relacionadas con la gastronomía en general, está experimentando un proceso de homogeneización.

Tradicionalmente, la comida ha estado también íntimamente ligada a los tiempos de producción de los alimentos, de ahí que en las distintas épocas del año tuviesen mayores protagonismos determinados platos y preparaciones. No solo el ciclo productivo anual marcaba el calendario culinario, sino que también el tipo de trabajo a realizar determinaba a veces un tipo de comida específica. Por otro lado, hay platos propios de los ciclos estacionales del año, relacionados con el frio y el calor. Es el caso de los escabeches y gazpachos, consumidos en verano. Por el contrario actividades productivas que requerían un gran esfuerzo físico se vinculaban con alimentos más grasos y de mayor valor energético. 
Además del calendario estacional y de su relación con los ciclos laborales, a lo largo del año existen también ciclos festivos durante los cuales tienen especial protagonismo ciertos platos y alimentos debido a las prohibiciones marcadas por la liturgia, como por ejemplo la Cuaresma en la religión católica, en la que los viernes se prohíbe comer carne. De ahí la importancia que tiene el potaje en nuestro territorio, un plato elaborado sin carne a base de legumbre, verdura y pescado. Lo mismo ocurre con determinados dulces, como las torrijas, muy típicas de Semana Santa, los Huesecillos del Santo en otoño, el turrón y el roscón en Navidad, etc.

Ahora bien, al margen de esos platos característicos de un ciclo, existen otros específicos asociados a fechas concretas, es el caso de las comidas típicas de determinadas fiestas de año y de las patronales. La mayoría de estas comidas se realizan en grupo, en un acto de comensalismo grupal. Comer juntos es uno de los fundamentos de la identidad y continuidad culturales de las comunidades. Es un momento de intercambio social y de comunicación, y también de afirmación y renovación de los lazos que configuran la identidad de la familia. En ocasiones, sobre todo en las celebraciones de fiesta de fin de vendimia, fiesta del azafrán, del ajo, de la castańa, etc., se evoca un pasado agrícola y se exalta lo folclórico y el valor de ese producto para la comunidad. También se ponen de relieve en estas celebraciones a través de la comida comunal los valores de buena vecindad y diálogo intercultural. Muchos de estos productos se exhiben u ofrecen al público a través de prácticas ritualizadas, regidas bajo normas de hospitalidad, como por ejemplo el pisado de la uva, pero ahora con una nueva resignificación, la de exaltarlo y revalorizarlo.

Al igual que sucede con los rituales, antes tratados, a la vista de la enorme implicación de dimensiones técnicas, kinésicas, simbólicas, instrumentales, cognitivas, emocionales, etc., en las manifestaciones culturales relacionadas con la gastronomía y la comensalidad resulta urgente olvidar también clasificaciones simplificadoras que atribuyan al curso de estas manifestaciones diversos grados de tangibilidad.

A la vista de las reflexiones aquí plasmadas resulta imprescindible, en el contexto de la cultura, considerar de manera unitaria los siempre citados planos: material e inmaterial. Debe contemplarse especialmente dicha perspectiva holística tanto en los procesos de documentación, como de exhibición, de exposición y de comunicación. Escindir todas estas dimensiones de la cultura y reducirlas dos categorías separadas e inconexas, una, la que conserva lo material y la otra, la que recoge lo inmaterial, limita la comprensión de cada uno de los componentes citados como elementos integrantes de un único sistema. El resultado que arroja dicha actitud dificulta el conocimiento y la interpretación de cada manifestación cultural inmaterial como proceso particular por el que un grupo humano se relaciona con su medio. 